\title{
HELLP SYNDROME, REVERSIBLE POSTERIOR LEUKOENCEPHALOPATHY SYNDROME AND ECLAMPSIA
}

\author{
Anderson Kuntz Grzesiuk', Renato Melo ${ }^{2}$, Ademar Rodrigues Carvalho ${ }^{3}$
}

Pre-eclampsia and eclampsia are two clinical situations that are exclusively associated with pregnancy. Symptoms typically begin after the $24^{\text {th }}$ week of pregnancy, and are characterized by arterial hypertension, edema and proteinuria; in eclampsia, seizures also happen'. Pre-eclampsia and eclampsia figure among the three most important causes of death in pregnancy. Among the complications of eclampsia, HELLP syndrome figures prominently as a cause of aggregated morbidity and of mortality. This syndrome is characterized by microangiopathic hemolytic anemia, increase of circulating liver enzymes and thrombocytopenia. It is an important complication of the last third of pregnancy, and it typically happens in women with known diagnosis of pre-eclampsia, although it has also been described in women without this diagnosis, as originally described by Weinstein in $1982^{2}$.

Neurological complications of eclampsia include mental confusion, seizures, cortical blindness, deficits in the visual fields, visual blurring and headaches. At neuroimaging, abnormalities include cortical edema and sometimes intracerebral hemorrhage. At pathology, typically signs include cortical and subcortical hemorrhagic petechiae, mostly in the parieto-occipital region'. In 1996, Hinchey and coworkers described what is currently known as reversible posterior leukoencephalopathy syndrome (RPLS). In this syndrome, neuroimaging demonstrates presence of cortical and subcortical edema, especially in the posterior regions of the brain (mainly parieto-occipital). The syndrome is reversible when properly and quickly treated. This syndrome has also been described in cases of hypertensive encephalopathy, eclampsia, hypertension associated with renal insufficiency and also as a complication of therapy with immunosuppressants or antineoplastic medications ${ }^{3}$.

We describe a case of association between HELLP syndrome and RPLS in a patient with eclampsia. This pathological association is poorly described. As up to the time of this writing, only four cases have been reported in the English medical literature ${ }^{4-7}$. This report was approved by the Ethics Committee of Santa Rosa Hospital.

\section{CASE}

A 34-year old woman, white, primigesta, without documented history of hypertension, diabetes, seizures or abortion. During the $32^{\text {nd }}$ week of pregnancy, she developed hypertension (her arterial pressure was normal until the $31^{\text {st }}$ week of pregnancy) which ultimately led to premature interruption of her pregnancy at the $34^{\text {th }}$ week, through cesarean delivery. At the time of the interruption, her pressure was $200 \times 130 \mathrm{mmHg}$. She presented a generalized tonic-clonic seizure just before the surgical act, medicated with intravenous (IV) magnesium sulphate. The cesarean happened without further intercurrences and she delivered a female child, weighting 1,725 grams, in good overall health conditions. The parturient was transferred into the intensive care unit (ICU), where she presented other episodes of seizures, only controlled after administration of IV phenytoin. Neurologic exam, conducted a few hours after her admission, showed a drowsy patient in confusional state. She also reported visual blurring and presented bilateral Babinski sign. MRI showed hypersignal in $\mathrm{T} 2$ and Flair, cortical and subcortical, more intense in the occipital, parietal and frontal lobes, without contrast enhancement or restricted diffusion (Fig 1). Image was suggestive of RPLS. Biochemical analyses showed elevation of hepatic transaminases; AST was $858 \mathrm{U} / \mathrm{L}$ (normal range $=11-39 \mathrm{U} / \mathrm{L}$ ) and ASL was $254 \mathrm{U} / \mathrm{L}$ (10-37 U/L). Other exams were: creatinine $=2.55 \mathrm{mg} / \mathrm{dL}(0.4-1.4$ $\mathrm{mg} / \mathrm{dL}$ ); lactic dehydrogenase=3,895 U/L (200-480 U/L); total bilirubins $=1.15 \mathrm{mg} / \mathrm{dL}(<1.2 \mathrm{mg} / \mathrm{dL})$; direct bilirubins $=0.48 \mathrm{mg} / \mathrm{dL}$ $(<0.4 \mathrm{mg} / \mathrm{dL})$; indirect bilirubins $=0.67 \mathrm{mg} / \mathrm{dL}(<0.4 \mathrm{mg} / \mathrm{dL})$. Her hematocrit was $25.1 \%$ (36-45\%); hemoglobin was $8.6 \mathrm{~g} / \mathrm{dL}$ (12.3$15.3 \mathrm{~g} / \mathrm{dL})$. White cells were $14,800 / \mathrm{mm}^{3}\left(4,000-11,000 \mathrm{~mm}^{3}\right)$ and platelets were $50,000 / \mathrm{mm}^{3}$ (150000-450000). Findings were suggestive of HELLP syndrome.

Intensive care treatment included the use of sodium nitroprusside for blood pressure control, as well as IV phenytoin for controlling the seizures. Hemotherapy with blood and platelet transfusions was used to correct the hematimetrics deficiencies. With the clinical intervention, she showed neurological improvement over the subsequent 72 hours. New MRI, performed 5 days after her admission (Fig 2), showed significant radiological improvement; there were only small areas of edema in the occip-

\section{HELLP, LEUCOENCEFALOPATIA REVERSÍVEL POSTERIOR E ECLÂMPSIA}

Intensive Care Unit, Santa Rosa Hospital, Cuiabá MT, Brazil: ${ }^{1}$ Neurologist; ${ }^{2}$ Intensive Care Specialist; ${ }^{3}$ Obstetrician.

Received 11 February 2009, received in final form 2 July 2009. Accepted 16 July 2009.

Dr. Anderson Kuntz Grzesiuk - Rua Custódio de Mello630 / 103 - 78030-435 Cuiabá MT - Brasil. E-mail: neuroakg@terra.com.br 


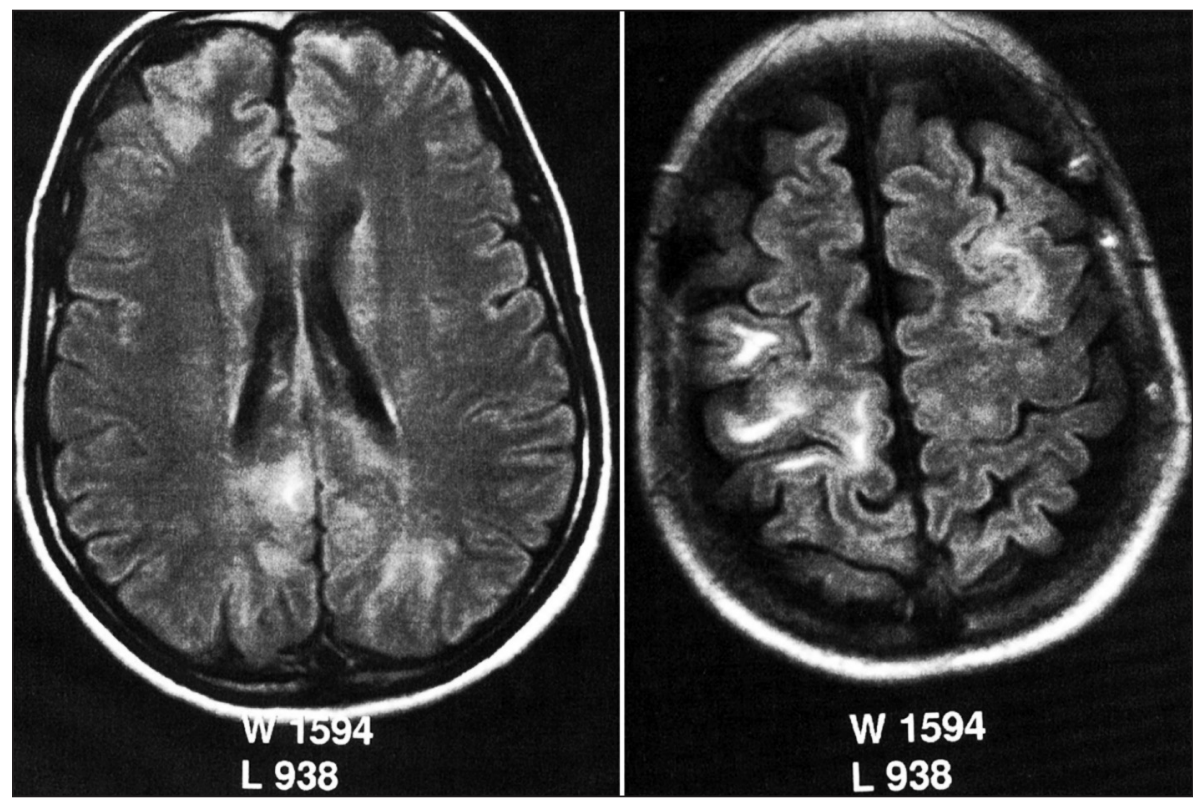

Fig 1. Axial FLAIR MRI showing hyperintense signal in white matter on occiptal, parietal and frontal lobes, without gadoliniun enhancement.
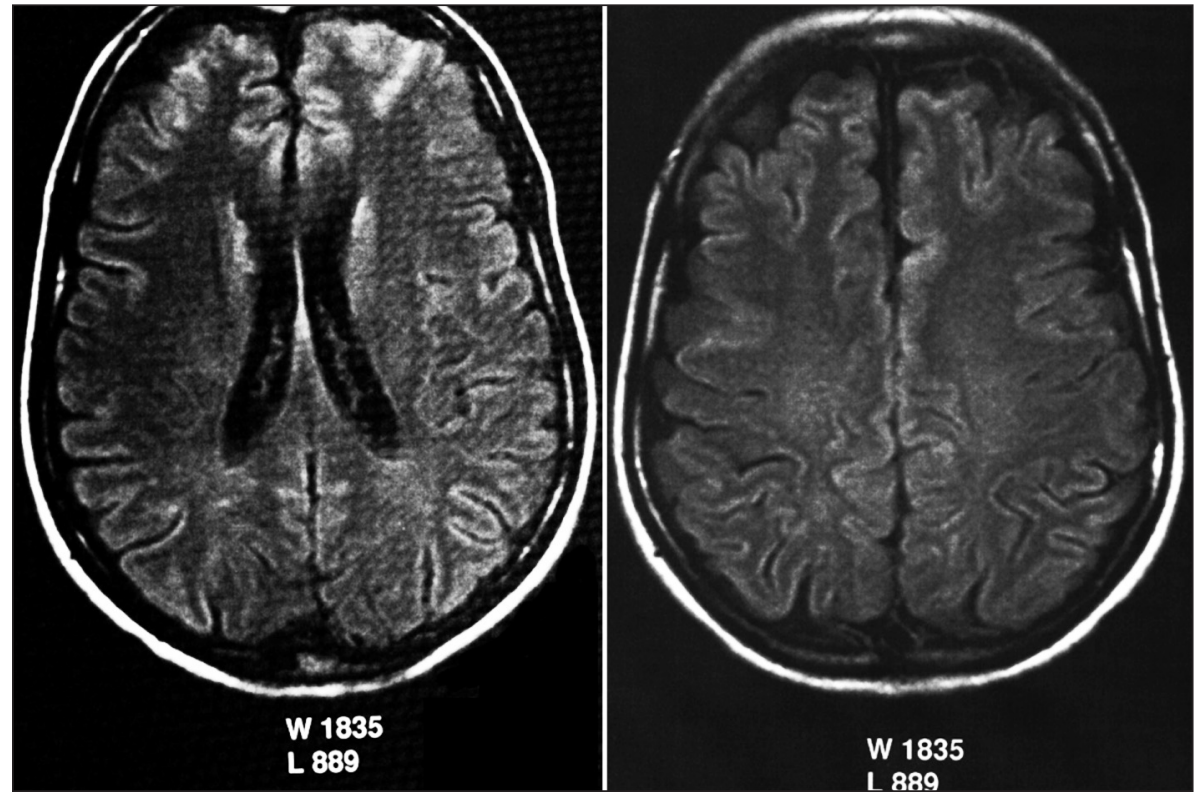

Fig 2. Axial FLAIR MRI done 5 days later, showing important reduction on hyperintensities in white matter.

ital and frontal lobes. She was discharged from the ICU seven days after admission, without neurological abnormalities.

\section{DISCUSSION}

HELLP syndrome is rare before the $20^{\text {th }}$ week of pregnancy. In $1 / 3$ of the cases it happens in the immediate post-natal phase. It is one of the most important complications of eclampsia. Hematologic (intravascular disseminated coagulation) and cardio-pulmonary events (pulmonary edema, acute cardiac insufficience) are commonly observed. Neurological alterations (cerebral bleeding, hypoxic-ischemic encephalopathy) are seen in only $4.5 \%$ of the patients ${ }^{8}$. Feske et al. showed that endothelium dysfunctions are likely important in the genesis of the syndrome, based on observing the similarities of HELPP and other vascular pathologies, such as thrombotic thrombocytopenic purpura and hemolytic-uremic syndrome. In these syndromes, the endothelium would be directly damaged by factors such as vasospasm, ischemia, platelet activation, increase in the levels of vasoactives mole- 
cules such as serotonin and thromboxane A-2, activation of the coagulation system, and impairment in the action of the normal placentally mediated adaptations to prostacyclin, nitrous-oxide, as well other endothelial mediators of the vascular tone and of vascular permeability ${ }^{5}$. Indeed, the vasoactive mechanism, with damage and loss of the cerebral vascular auto-regulation, is the proposed basic mechanism suggested by Hinchey et al. in the original article describing the syndrome. They also suggested that hypertensive encephalopathy and eclampsia share similar pathophysiological mechanisms ${ }^{3}$.

The clinical observation that the vascular system in the anterior region of the brain have more dense sympathetic innervations, as compared to the posterior regions, may at least explain the predilection for edema in the posterior regions of the brain, especially in the parieto-occipital regions $^{9-11}$. However, it is not uncommon to see areas of edema in the cerebellum, brainstem, and even in the anterior regions of the brain ${ }^{4}$, as in the case reported herein. The hypothesis that endothelials factors other than vasoconstriction may explain the RPLS, is also supported by case reports of RPLS and HELLP syndrome in patients without arterial hypertension, or even in patients treated by cytotoxic agents such as cyclosporine or tacrolimus ${ }^{3,6,8}$. Furthermore, MRI characteristically show areas of a hypersignal in $\mathrm{T} 2$ in the posterior lobe, basal ganglia and brainstem and this lesions probably reflect edema instead of ischemic damage ${ }^{8}$. This last assumption, is supported by the reversibility of the clinical component, and also because, of the medial portion of the occipital lobe, as well as the calcarine fissure, are typically spared.

In this article we reported and raised attention for a rare association between HELLP syndrome, RPLS and ec- lampsia. It seems that the endothelium vasogenic mechanisms led to the neurologic manifestations manifested by our patient. The effective and fast correction of the pressure levels, associated to the quick recognition and treatment of the HELLP syndrome translated into good outcomes and total reversibility of the sings, as previously suggested by the medical literature.

\section{REFERENCES}

1. Pack AM, Morell MJ. Neurologic disease during pregnancy. In Rowland LP (Ed). Merrit's Neurology. $11^{\text {th }}$ Ed. Philadelphia: Lippincott Williams \& Wilkins, 2005:1112-1119.

2. Weinstein L. Syndrome of hemolysis, elevated liver enzymes, and low platelet count: a severe consequence o hypertension in pregnancy. Am J Obstet Gynecol 1982;142:159-167.

3. Hinchey J, Chaves C, Appignani B, et al. A reversible posterior leukoencephalopathy syndrome. N Engl J Med 1996;334:494-500.

4. Peng WX, Nakaii M Matsushima T, Asakura H. Atypical case of reversible posterior leucoencephalopathy syndrome associated with puerperal HELLP syndrome. Arch Gynecol Obstet 2008;278:269-271.

5. Feske SK, Sperling RA, Schwartz RB. Extensive reversible brain magnetic resonance lesions in a patient with HELLP syndrome. J Neuroimag 1997;7:247-250.

6. Negro A, Zuccoli G, Regolisti G, Mastrangeli S, Rossi E. Reversible posterior leukoencephalopathy associated with postpartum HELLP syndrome. Eur J Intern Med 2005;16:291-293.

7. Morton A, Higgins S, Mullins B. HELLP, eclampsia and posterior reversible encephalopathy in a young woman with streak ovary syndrome. Austr N Z J Obstet Gynaecol 2005;45:173-174.

8. Marano E, Scuteri N, Vacca G, Orefice G. HELLP syndrome with reversible posterior leukoencephalopathy. Neurol Sci 2003;24:82-84.

9. Sheth RD, Riggs JE, Bodenstenier JB, Gutierrez AR, Ketonen LM, Ortiz OA. Parietal occipital edema in hypertensive encephalopathy a pathogenic mechanism. Eur Neurol 1996;36:25-28.

10. Garg RK. Posterior leukoencephalopathy syndrome. Postgrad Med J 2001;77:24-28

11. Lamy C, Mas JL. Reversible posterior leukoencephalopathy: a new syndrome or a new name for an old syndrome? Presse Med 2001;30:915-920. 